www.jmscr.igmpublication.org Impact Factor 5.244

Index Copernicus Value: 83.27 ISSN (e)-2347-176x ISSN (p) 2455-0450 crossref DOI:_https://dx.doi.org/10.18535/jmscr/v4i12.108

\title{
Study of Pre-Analytical and Post-Analytical Errors in Hematology Laboratory in A Tertiary Care Hospital
}

\author{
Authors \\ Dhiraj Kumar B. Shukla ${ }^{1}$, Sujata R. Kanetkar ${ }^{2}$, Suchi G. Gadhiya ${ }^{3}$, Shivani Ingale ${ }^{3}$ \\ ${ }^{1}$ Assistant Professor, Department of Pathology, Krishna Institute of Medical Sciences, Karad \\ ${ }^{2}$ Professor and Head, Department of Pathology, Krishna Institute of Medical Sciences, Karad \\ ${ }^{3}$ Tutor, Department of Pathology, Krishna Institute of Medical Sciences, Karad \\ Corresponding Author \\ Dr Dhiraj Kumar B. Shukla
}

Assistant Professor, Department of Pathology, Krishna Institute of Medical Sciences, Karad

Email: drshukla.patho@gmail.com

\begin{abstract}
Introduction: Laboratories play an important role in the diagnosis and management of the disease. In the modern day diagnostics, with the advent of technologies and automation in the laboratories, the manual workload has decreased. Automation has reduced the number of errors but still few errors do occur. Present study was undertaken to evaluate different types \& frequencies of pre-analytical and post-analytical errors in hematology laboratory of a tertiary care hospital.
\end{abstract}

Methods: Present study is a prospective study. All the samples received in hematology laboratory of our hospital over a period of one year were included in the study. All the pre-analytical variables such as clotted samples, quantity not sufficient, wrong sample, sample without label, wrong label and post analytical variables such as printing error, delayed dispatch of report and reports misplaced were noted \& studied.

Results: In the present study total 1, 21,470 samples were received in hematological laboratory over a period of one year. Preanalytical errors were noted in 1,218 samples. Clotted sample was noted in 573 cases, inadequate quantity in 213 cases, hemolysed sample in 176 cases, improper requisition form in 114 cases, improper container in 92 cases \& diluted sample in 50 cases. Post analytical errors were noted in 213 samples. Delayed dispatch of report was noted in 107 cases, printing errors in 69 cases and misplaced reports in 37 cases.

Conclusion: Preanalytical and post analytical errors in hematological laboratory can be reduced by regular analysis of the variables \& regular education and training of staff concerned with blood collection \& handling of blood samples.

Key Words:, Postanalytical errors, Hematology, Training.

\section{INTRODUCTION}

Laboratories play an important role in patient care and diagnoses in a tertiary care hospital. With recent advances in technologies and introduction of automation in hematology \& clinical pathology, the incidences of human error have reduced but still there are many variables which can influence the laboratory results. ${ }^{1}$ Modern day diagnoses are 


\section{JMSCR Vol||04||Issue||12||Page 14964-14967||December}

heavily dependent upon reliable laboratory data. It is therefore pertinent to ensure credibility of the results, emanating from the clinical laboratories. ${ }^{2}$ Quality assurance in the hematology laboratory is intended to ensure laboratory users of standardized, reliable test results. ${ }^{3}$ Errors arising in the hematology laboratory sample processing are generally categorized into Pre-analytical, Analytical and Postanalytical. ${ }^{4,5,6,7}$ Out of these three groups of error, Pre-analytical and post analytical errors accounts for the maximum errors. The present study was undertaken with an objective to evaluate different types and frequencies of Pre-analytical and post analytical errors in hematology laboratory of a tertiary care hospital.

\section{METHODS}

Present study is a prospective study. All the samples received in hematology laboratory of our hospital over a period of one year (July2015June2016) were included in the study. All the preanalytical variables such as clotted samples, quantity not sufficient, wrong sample, sample without label, wrong label and post-analytical variables such as printing error, delayed dispatch of report and reports misplaced were noted \& studied.

\section{RESULT}

During the study period of one year, total 1, 21,470 samples were received in hematology laboratory.

Total errors reported were in 1431(1.18\%) samples. Pre-analytical errors were noted in $1218(1.003 \%)$ cases and post analytical cases were noted in $213(0.17 \%)$ cases. No analytical error was reported during the study period. The Pre-analytical errors noted were Clotted samples, Quantity not sufficient, Hemolyzed samples, improper requisition form, improper container, and Diluted samples (Table 1). Clotted sample $(47.05 \%)$ was the most common pre-analytical error followed by quantity not sufficient (17.49 $\%)$. Hemolyzed was received in $14.45 \%$ of cases whereas samples with improper requisition constituted $9.36 \%$ cases. Use of improper container was noted in $7.55 \%$ of cases and diluted samples were received in $4.10 \%$ cases.

Table 1 - Distribution of cases with pre-analytical errors.

\begin{tabular}{|l|c|c|c|}
\hline Pre-analytical error & Number of samples & \% error & \% error in total samples \\
\hline Clotted samples & 573 & $47.05 \%$ & $0.47 \%$ \\
\hline Quantity not sufficient & 213 & $17.49 \%$ & $0.17 \%$ \\
\hline Hemolysed samples & 176 & $14.45 \%$ & $0.14 \%$ \\
\hline Improper requisition form & 114 & $9.36 \%$ & $0.09 \%$ \\
\hline Improper container & 92 & $7.55 \%$ & $0.08 \%$ \\
\hline Diluted samples & 50 & $4.10 \%$ & $0.04 \%$ \\
\hline \multicolumn{1}{|c|}{ Total } & 1218 & $100 \%$ & $1.003 \%$ \\
\hline
\end{tabular}

Post analytical errors noted were Delayed dispatch of reports, printing errors in reports and misplaced reports (Table 2). Most common post analytical error noted was delayed dispatch of reports

Table 2- Distribution of cases with post analytical errors.

\begin{tabular}{|l|c|c|c|}
\hline Post Analytical Errors & No. of sample & \% of error & \% in total sample \\
\hline Delayed dispatch & 107 & $50.23 \%$ & $0.09 \%$ \\
\hline Printing error & 69 & $32.40 \%$ & $0.05 \%$ \\
\hline Misplaced report & 37 & $17.37 \%$ & $0.03 \%$ \\
\hline & 213 & $100 \%$ & $0.17 \%$ \\
\hline
\end{tabular}
printing error $(32.40 \%)$. Misplaced reports were observed in $17.37 \%$ of cases. 


\section{DISCUSSION}

During the study period of one year, total 1, 21,470 samples were received in hematology laboratory.

Total errors reported were in 1431 (1.18\%) samples. In the study done by Sadiq $\mathrm{F}$ et $\mathrm{al}^{8}$ errors were detected in $1.20 \%$ of samples which is in concordance with the present study.

Pre-analytical errors were noted in 1218 $(1.003 \%)$ cases, which constituted the major source of error in the laboratory. Plebani and Carraro $^{4}$ in their study observed preanalytical error to be the major source of error in laboratory and similar finding was reported byBonini and colleagues $^{5}$. Post analytical errors were noted in $213(0.17 \%)$ cases. No analytical error was reported during the study period.

The present study revealed clotted samples (47.05\%) being the most common Preanalytical error. Same result was found by studies done by Bharat $\mathrm{V}$ et $\mathrm{al}^{9}$ and Sumera Nazet $\mathrm{al}^{2}$.The common reason of which is improper mixing of sample and inadequate EDTA.

Quantity not sufficient was the reason for $17.49 \%$ of preanalytical errors.

Hemolyzed sample was noted in $14.45 \%$ of cases. Bharat Vet $\mathrm{al}^{9}$ in their study had $21.56 \%$ of cases with hemolyzed sample. Akan et $\mathrm{al}^{10}$ and Sadiq F et $\mathrm{al}^{8}$ in their study observed that frequency of hemolysis was more during night shifts.

Improper requisition form was noted in $9.36 \%$ of cases. Bharat Vet $\mathrm{al}^{9}$ in their study observed this error in $13.72 \%$ of cases which is almost similar to our findings. Improper container was observed in $7.55 \%$ of cases. Similar observation was made by Bharat Vet al ${ }^{9}$.

Delayed dispatch of report or prolong turnaround time was noted in $50.23 \%$ of cases. Sadiq Fet al ${ }^{8}$ in their study observed delayed dispatch of report in $21.64 \%$ of cases. They observed that the reason for this is inadequate information to laboratory porters about shifting of patient from one ward to another location.

Printing error was observed in $32.40 \%$ of cases. Bharat $\mathrm{V}$ et $\mathrm{al}^{9}$ during their study observed this error in $12.50 \%$ of cases. The main reason for this typing of error was illegible writing on the requisition form.

Misplaced reports were reported in $17.37 \%$ of cases. Bharat $\mathrm{V}$ et $\mathrm{al}^{9}$ during their period of study observed misplaced reports in $25 \%$ of cases which has been attributed to uncoordinated shifting of patient and clinicians not being informed about reports.

\section{CONCLUSION}

Preanalytical and post analytical errors in hematological laboratory can be reduced by regular analysis of the variables \& regular education and training of staff concerned with blood collection \& handling of blood samples.

\section{REFRENCES}

1. Chawla R. Goswami V. Tayal D. Malika $\mathrm{V}$. Identification of types of pre-analytical errors in the clinical chemistry laboratory: 1 year study of GB Pant Hospital. Lab Med. 2010; 41: 89-92.

2. Sumera Naz, Arshad Mumtaz, Agha Sadaruddin. Preanalytical Errors and Their Impact on Tests in Clinical Laboratory Practice.PakJMed Res, 2012; 51:27-30.

3. VikramNarang, HarsimranKaur, Pavneet Kaur Sethi\& et al. Preanalytical Errors in Hematology Laboratory-an Avoidable Incompetence. Iran J Pathol.2016; 11(2):151-154.

4. Plebani M, Carraro P. Mistakes in stat laboratory: types and frequency. ClinChem Lab Med 1997; 43:1348-1351.

5. Bonini P, Plebani M, Ceriotti F, Rubboli F. Errors in laboratory medicine. ClinChem Lab Med 2002; 48:691-698.

6. Plebani M. Errors in clinical laboratories or errors in laboratory medicine?. Clin Chem Lab Med 2006; 44:750-759.

7. Patra S, Mukherjee B,Das Kumar A. Preanalytical Errors In The Clinical Laboratory And How To Minimize Them. 
International Journal of Bioassays 2013;2(3):551-553.

8. Sadiq F, Yasmeen F. Frequency of errors in clinical laboratory practice. Iranian Journal of Pathology. 2014;9(1):45-49.

9. Vinay B, Tiwari G. A reflection on pre and post analytical errors in Hematology Laboratories. Int. J. Adv. Biol. Sci. 2015;2(2):190-195.

10. Akan OA, Elmali E, Karaeren Z. Evaluation of pre-analytical errors in clinical laboratory. Lab Med 2006;37 (8):478-480. 